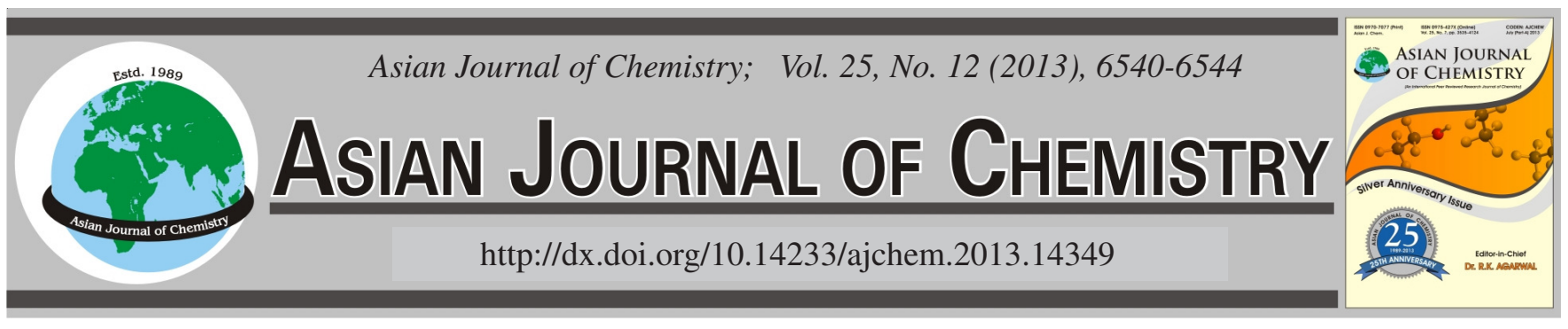

\title{
Synthesis and Characterization of Human Body Trace Elements Substituted Hydroxyapatite for a Bioactive Material
}

\author{
Shitao Song, Suxia Wu*, Qi Lian, Youshun Peng, Xuefang Zheng and Zhiwei Zhang
}

College of Physics and Chemistry, Hebei Normal University of Science \& Technology, Qinhuangdao 066600, P.R. China

*Corresponding author: Tel/Fax:+86 335 2039067; E-mail: suxiawu@163.com; sst1210@163.com

Zinc, manganese and ferrus substituted hydroxyapatite (HA) have been synthesized by sol-gel technique. The structure, morphology and biological activity of the synthetic samples were characterized by XRD, SEM and amino acid adsorption experiments. Comparative studies were carried out with hydroxyapatite, zinc substituted hydroxyapatite, manganese substituted hydroxyapatite and ferrum substituted hydroxyapatite. Manganese and ferrum substitution in hydroxyapatite reduced its crystallinity and particles size and increased the specific surface area of hydroxyapatite. Biological activity studies evidenced that the presence of zinc, manganese and ferrum in hydroxyapatite improved the biological activity of hydroxyapatite and Zn-hydroxyapatite showed better biological activity than the others. This study shows that the trace elements substituted hydroxyapatite have very good biocompatibility, which is an excellent bone substitution material.

Key Words: Hydroxyapatite, Sol-gel method, Amino acid, Biological activity.

ᄂ - - - - - - - - - - - - - - - - - - - - - - - - - -

\section{INTRODUCTION}

Hydroxyapatite (HA) is the major inorganic constituent of bone and teeth. Due to the chemical similarity between hydroxyapatite and mineralized bone of human tissue, synthetic hydroxyapatite exhibits strong affinity to host hard tissues. Formation of chemical bond with the host tissue offers hydroxyapatite a greater advantage in clinical applications than most other bone substitutes ${ }^{1}$. Hydroxyapatite has been extensively used in various forms for bone repairs and as coatings for metallic prostheses owing to its high bioactivity and particular adsorbability for various ions and organic molecules. However, the poor mechanical properties and biological properties of hydroxyapatite hindered its application. In order to improve the properties of hydroxyapatite, there have been numerous attempts to produce synthetic hydroxyapatite. Ionic substitutions have been an effective tool to improve the properties of hydroxyapatite. Hydroxyapatite has a hexagonal crystal structure and an array of $\mathrm{PO}_{4}{ }^{3-}$ tetrahedra held together by $\mathrm{Ca}^{2+}$ and hydroxyl ions in the structure of hydroxyapatite ${ }^{2}$. This structure allows the $\mathrm{Ca}^{2+}$ site substituted by $\mathrm{Ti}^{4+}, \mathrm{Sr}^{2+}, \mathrm{Mg}^{2+}$ etc. and the $\mathrm{PO}_{4}{ }^{3-}$ site by $\mathrm{CO}_{3}{ }^{2-}, \mathrm{SiO}_{4}{ }^{4-}$ etc. as well as the $\mathrm{OH}^{-}$ group by $\mathrm{F}^{-}, \mathrm{CO}_{3}{ }^{2-}$ etc. Ionic substitutions can affect the surface charge, lattice parameters, crystallinity and morphology which can result in changes in thermal stability, mechanical properties, solubility and bioactivity of hydroxyapatite ${ }^{3-10}$. Hydroxyapatite substituted by $\mathrm{F}^{-}$exhibited increased thermal stability ${ }^{8,9}$. Hydroxyapatite modified with $\mathrm{Ti}^{4+}$ ions showed better photocatalytic and antimicrobial activity ${ }^{5} \mathrm{Mg}^{2+}$ ions in hydroxyapatite structure could affect its crystallization and thermal stability promoting the formation of $\mathrm{TCP}^{10} . \mathrm{Sr}^{2+}$ in hydroxyapatite could increase the solubility of hydroxyapatite and stimulate the bone formation ${ }^{6}$. As a naturally present trace element in bone, zinc can stimulate bone growth and bone mineralization ${ }^{11}$. Zinc has a direct effect on osteoblastic cells in vitro and an inhibitory effect on osteoclastic bone resorption in vivo ${ }^{12,13}$ in addition to its antimicrobial activity ${ }^{14} \cdot \mathrm{Zn}^{2+}$ substituted hydroxyapatite nanocarriers exhibited higher protein releases when compared to pure hydroxyapatite ${ }^{15}$. Incorporation of carbonate into hydroxyapatite has improved the biological activity because the incorporation of carbonate into hydroxyapatite caused a change in crystal morphology, a decrease in crystallinity, an increase in solubility and increases the local concentration of calcium and phosphate ions that are necessary for new bone formation ${ }^{16,17}$.

Zinc, manganese and ferrus are three important trace elements in human body, which have an important function to human health. In the present work, pure hydroxyapatite and zinc, manganese and ferrus substituted hydroxyapatite powders have been synthesized via sol-gel method using calcium nitrate and phosphorus pentoxide as calcium and phosphorus precursors. Comparative studies of their physicochemical 
properties were carried out with hydroxyapatite, zinc substituted hydroxyapatite, manganese substituted hydroxyapatite and ferrus substituted hydroxyapatite.

\section{EXPERIMENTAL}

Synthesis: The raw materials used in the synthesis of the hydroxyapatite powders were as follows: $\mathrm{Ca}\left(\mathrm{NO}_{3}\right)_{2} \cdot 4 \mathrm{H}_{2} \mathrm{O}$, $\mathrm{P}_{2} \mathrm{O}_{5}, \mathrm{Zn}\left(\mathrm{NO}_{3}\right)_{2} \cdot 6 \mathrm{H}_{2} \mathrm{O}, \mathrm{Mn}\left(\mathrm{CH}_{3} \mathrm{COO}\right)_{2} \cdot 4 \mathrm{H}_{2} \mathrm{O}$ and $\mathrm{Fe}\left(\mathrm{NO}_{3}\right)_{2} \cdot 9 \mathrm{H}_{2} \mathrm{O}$. All chemicals used in the experiments were of analytical purity, purchased from SINOPHARM without further purification. Deionized water was employed as the solvent.

Hydroxyapatite powders were synthesized by sol-gel method. Firstly, for pure hydroxyapatite synthesis, calcium nitrate tetrahydrate and phosphorus pentoxide were dissolved in ethanol, respectively to prepare the solutions. According to the $\mathrm{Ca} / \mathrm{P}$ molar ratio of 1.67 , the phosphorus pentoxide solution was added dropwise into calcium nitrate solution. The solution was rigorously stirred for $2 \mathrm{~h}$, heated in water bath at $60^{\circ} \mathrm{C}$ for $4 \mathrm{~h}$ and left for $12 \mathrm{~h}$ at room temperature. The gel obtained after aging was dried at $100^{\circ} \mathrm{C}$ for $12 \mathrm{~h}$ in a vacuum dry oven. Finally, the powders from dried gel were calcined in air at $700{ }^{\circ} \mathrm{C}$ for $12 \mathrm{~h}$ to obtain the hydroxyapatite powders using an electrical furnace and employing a heating rate of $10{ }^{\circ} \mathrm{C} / \mathrm{min}$. For $\mathrm{Zn}$ hydroxyapatite, Mn-hydroxyapatite and Fe-hydroxyapatite synthesis, zinc nitrate solution, manganese acetate solution and ferric nitrate solution were used, respectively. Other steps were the same as pure hydroxyapatite synthesis.

Characterization: The X-ray diffraction (XRD) patterns of the as-synthesized samples were obtained using Rigaku D/ max-2500/PC diffractometer in the $2 \theta$ range of $20-60^{\circ}$ with $\mathrm{Cu} \mathrm{K}_{\alpha}$ radiation $(0.154 \mathrm{~nm})$. Crystallographic identification of the phases of the samples was accomplished by comparing the experimental XRD pattern with standard data compiled by the International Center for Diffraction Data (ICDD). The morphology of as synthesized samples were observed using KYKY2800 scanning electron microscope (SEM), operated at an accelerating voltage of $20 \mathrm{kV}$. The ultraviolet absorption spectrum (UV) was done with Shimadzu UV2401 ultravoilet spectrometer.

Biological activity studies: Firstly, $10 \mathrm{mg} \mathrm{L}^{-1}$ of amino acid solution was prepared by addition of amino acid into distilled water. The appropriate amount hydroxyapatite samples were added into $10 \mathrm{mg} \mathrm{L}^{-1}$ of amino acid solution and stirred for $2 \mathrm{~h}$ to reach adsorption balance. After centrifugal separation, upper clear liquid was detected in wavelength range of 400-190 nm by ultraviolet spectrograph, using distilled water as reagent blank. Through contrast analysis of maximum absorption peaks in ultraviolet absorption spectrum, the biological activity of hydroxyapatite powders was evaluated.

\section{RESULTS AND DISCUSSION}

XRD phase analysis: Fig. 1 shows the XRD patterns of the as-synthesized samples under different concentration of $\mathrm{Ca}\left(\mathrm{NO}_{3}\right)_{2}$ solution. The peak positions were compared with JCPDS data for hydroxyapatite (JCPDS file No. 09-0432). It could be observed that the obtained XRD patterns were in good agreement with standard data for hydroxyapatite. When the concentration of $\mathrm{Ca}\left(\mathrm{NO}_{3}\right)_{2}$ solution was $0.5 \mathrm{~mol} / \mathrm{L}$, XRD patterns showed mainly broad peaks of hydroxyapatite and no characteristic peaks of impurities were observed. This suggested that the powders constitutes hydroxyapatite as a unique crystalline phase. The crystallinity of as-synthesized hydroxyapatite decreased together with minor $\mathrm{CaO}$ peaks with the increase of concentration of $\mathrm{Ca}\left(\mathrm{NO}_{3}\right)_{2}$ solution.

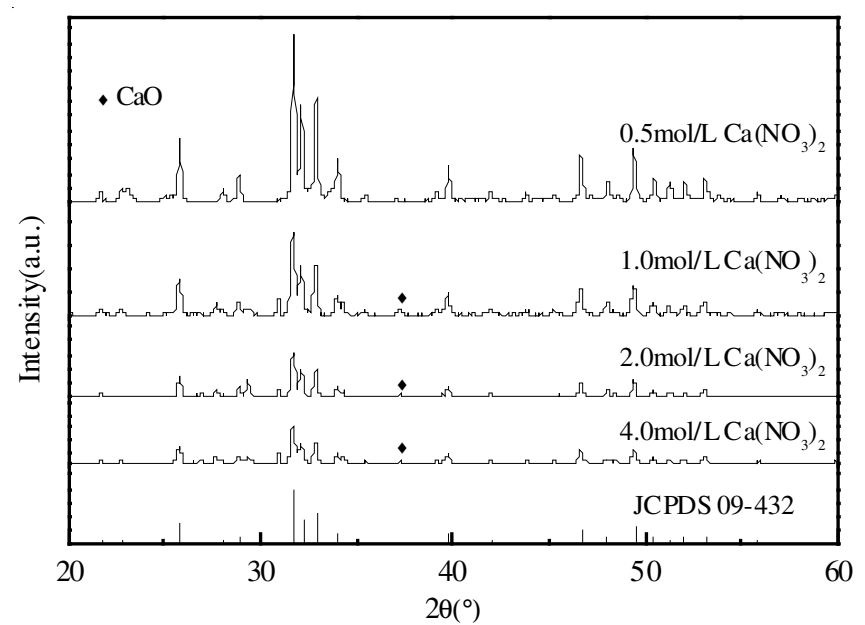

Fig. 1. XRD patterns of hydroxyapatite powders prepared under different concentration of $\mathrm{Ca}\left(\mathrm{NO}_{3}\right)_{2}$

The XRD patterns of the as-synthesized hydroxyapatite samples substituted by different trace metal elements are shown in Fig. 2. It could be observed that the XRD patterns of hydroxyapatite substituted by zinc, manganese and ferrus were in good agreement with standard data for hydroxyapatite (JCPDS file No. 09-0432). X-ray diffractometer results indicated that the substituted hydroxyapatite powders had the same crystal structure as hydroxyapatite. Furthermore, the diffraction peak strength of hydroxyapatite was different with different elements substitution. The crystallinity of as-synthesized hydroxyapatite decreased due to substituted elements.

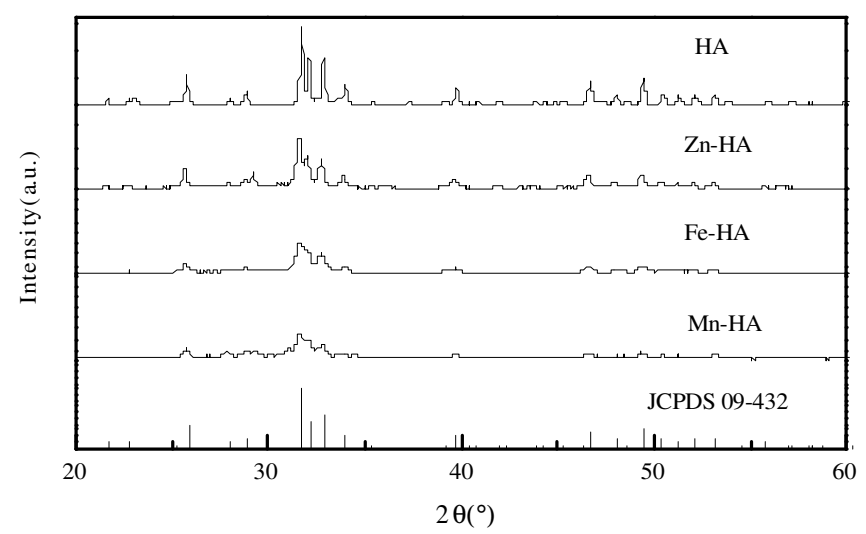

Fig. 2. XRD patterns of hydroxyapatite (HA) powders substituted with different element

Fig. 3 shows the XRD patterns of the as-synthesized samples with different amount of $\mathrm{Zn}$ substitution. It was obvious that the obtained XRD patterns were in good agreement with standard data for hydroxyapatite (JCPDS file No. 09-0432) in Fig. 3. The diffraction peak strength of hydroxyapatite decreased together with minor $\mathrm{CaO}$ and $\mathrm{CaZn}_{2}\left(\mathrm{PO}_{4}\right)_{2} \cdot \mathrm{H}_{2} \mathrm{O}$ peaks with 
the increase of $\mathrm{Zn}$ substitution amount and the intensity of the two types of diffraction peaks increased. It could be seen from Fig. 3 that the diffraction peak in the $2 \theta$ of $36.7^{\circ}$ attributed to $\mathrm{CaO}$ phase, which may be because that the zinc ion occupied the calcium hole, leading some calcium oxide in the framework.

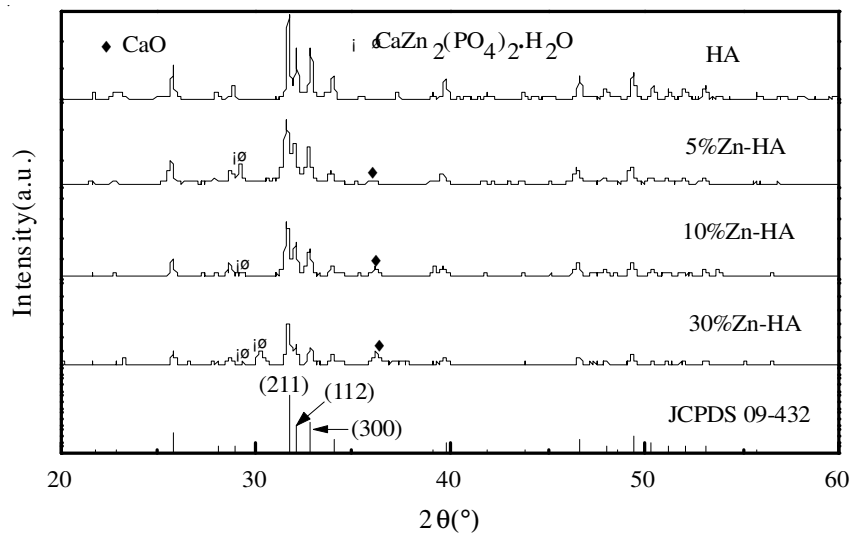

Fig. 3. XRD patterns of hydroxyapatite (HA) powders under different $\mathrm{Zn}$ substitution amount

The resolution of characteristic XRD peaks of hydroxyapatite corresponding to the reflections of (211), (112) and (300) fell, which indicated that the crystallinity of hydroxyapatite decreased with the increase of $\mathrm{Zn}$ substitution amount. The possible reasons for changes in crystal structure of $\mathrm{Zn}$ hydroxyapatite are as follows.

The $\mathrm{Zn}^{2+}$ ion radius of $0.074 \mathrm{~nm}$ is less than $\mathrm{Ca}^{2+}$ ion of $0.099 \mathrm{~nm}$. When $\mathrm{Ca}^{2+}$ ions are substituted by $\mathrm{Zn}^{2+}$ ions in the hydroxyapatite framework, the structure distortion happens and the diffraction peak of hydroxyapatite weakens and gradually broadens, which cause the crystallinity of hydroxyapatite decrease. The percentage of amorphous phase increases as $\mathrm{Ca}^{2+}$ ions are substituted by $\mathrm{Zn}^{2+}$ ions in the hydroxyapatite framework. $\mathrm{Zn}$ in hydroxyapatite induces a reduction in the crystallite size.

SEM images analyses: SEM images of the as-synthesized samples with different elements substitution are given in Fig. 4. With respect to the SEM images analyses, it was observed that hydroxyapatite, Zn-hydroxyapatite, Mn-hydroxyapatite and $\mathrm{Fe}$-hydroxyapatite consisted of loosely aggregated small particles and their surfaces were loose, coarse and porous. This revealed that the composite powders possesed a porous structure and high surface areas. The contrast analysis showed that substituted hydroxyapatite powders was of more obvious porous surface structure and larger specific surface area than hydroxyapatite. Among them, the zinc substituted hydroxyapatite exhibited smallest particles size and largest specific surface area, which further indicated zinc substituted hydroxyapatite had better biological adsorption properties.

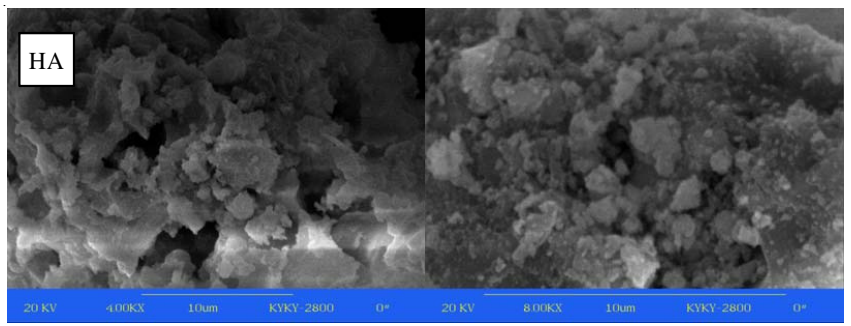

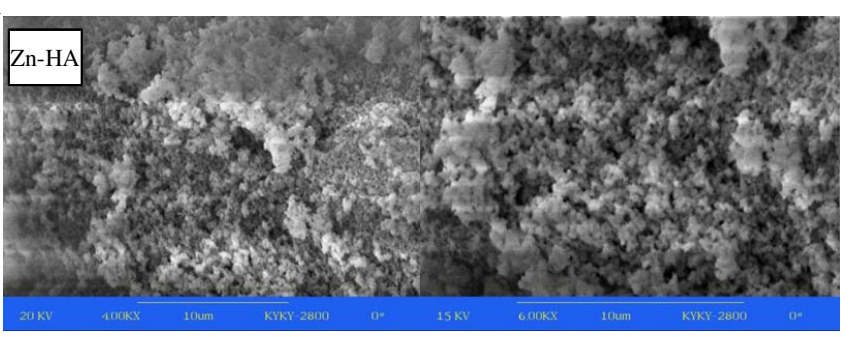
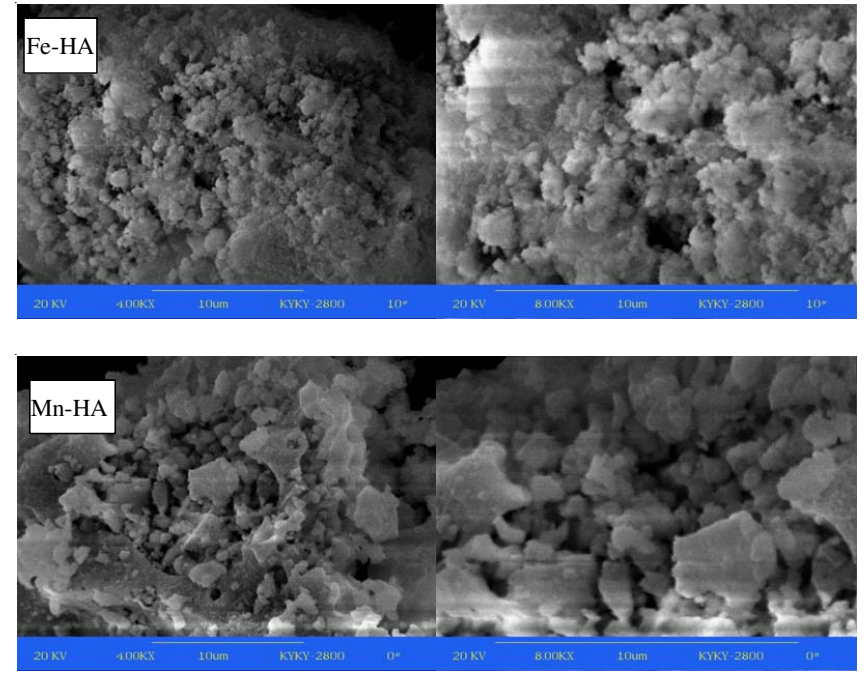

Fig. 4. SEM images of substituted hydroxyapatite powders

Biological activity analysis: The UV spectra of assynthesized samples are shown in Fig. 5. It could be seen that the intensity of maximum ultraviolet absorption peaks for amino acid solution increased apparently after adsorption by hydroxyapatite, which may be because that the formation of soluble molecules due to amino acid molecules combined with hydroxyapatite lead to the change of the ultraviolet absorption. This indicated that hydroxyapatite had obvious adsorption for amino acids. Furthermore, the hydroxyapatite powders synthesized with $0.5 \mathrm{~mol} / \mathrm{L}$ of $\mathrm{Ca}\left(\mathrm{NO}_{3}\right)_{2}$ had the strongest ultraviolet absorption peaks for amino acid solution, implying that it was of the stronger absorption ability for amino acid and the better biological activity.

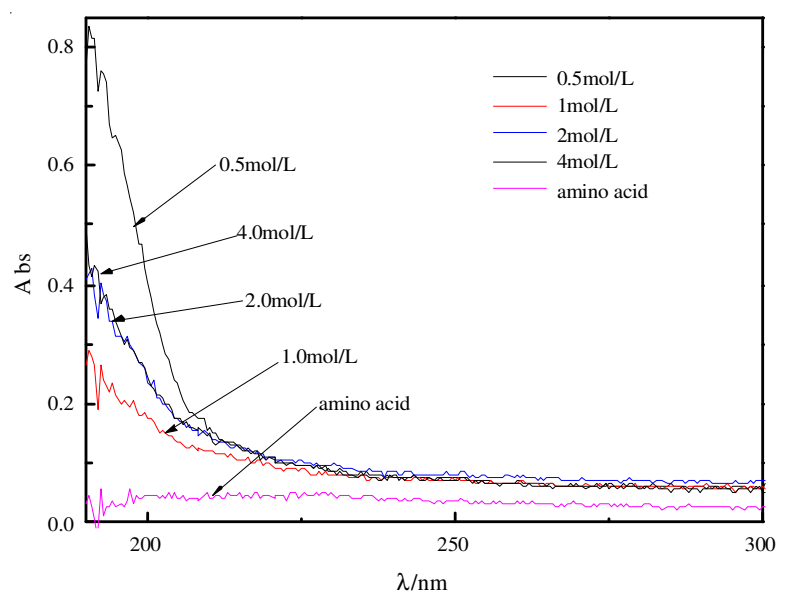

Fig. 5. UV spectra of amino acid before and after adsorption by hydroxyapatite

Fig. 6 shows the UV spectra of amino acid adsorbed by hydroxyapatite for different time. It can be seen that the 
adsorption rate of hydroxyapatite powders for amino acid was rapid and the adsorption reaction soon reached balance. This suggested that the adsorption of hydroxyapatite for bioactive substances could be completed on the moment. Therefore, when hydroxyapatite was transplanted into human body, the adsorption could quickly reach equilibrium in vivo environments.

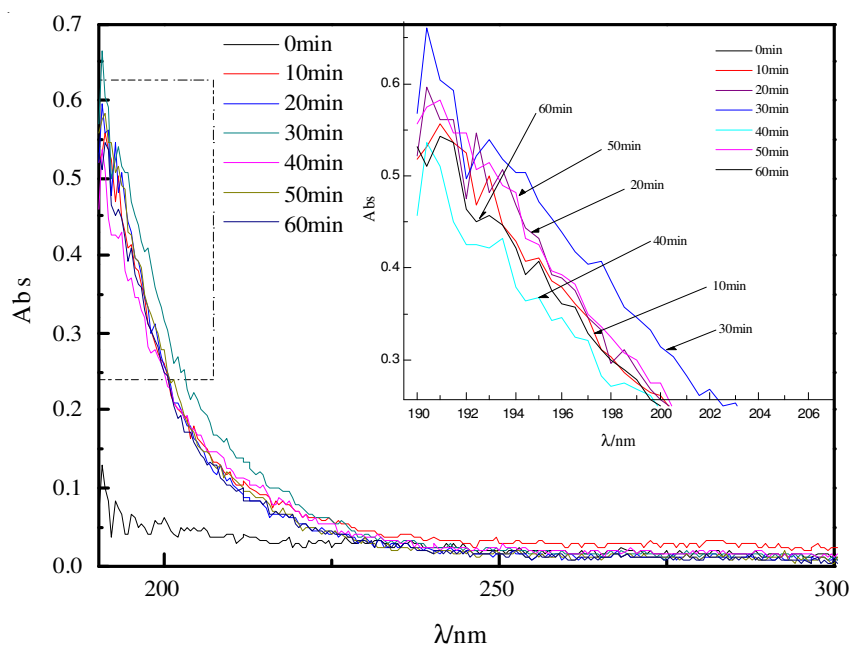

Fig. 6. UV spectra of amino acid adsorbed by hydroxyapatite for different time

Fig. 7 shows the UV spectra of amino acid adsorbed by hydroxyapatite in different $\mathrm{pH}$. The adsorption performances of hydroxyapatite for amino acid in different $\mathrm{pH}$ value were basic consistent and the $\mathrm{pH}$ value had less effect on the adsorption performances of hydroxyapatite for amino acid. Therefore, the biological activity of hydroxyapatite in various parts of human body was basically the same. The $\mathrm{pH}$ values of various parts of human body fluid are shown in Table-1. So, the hydroxyapatite powders could be widely used in various forms for bone repairs.

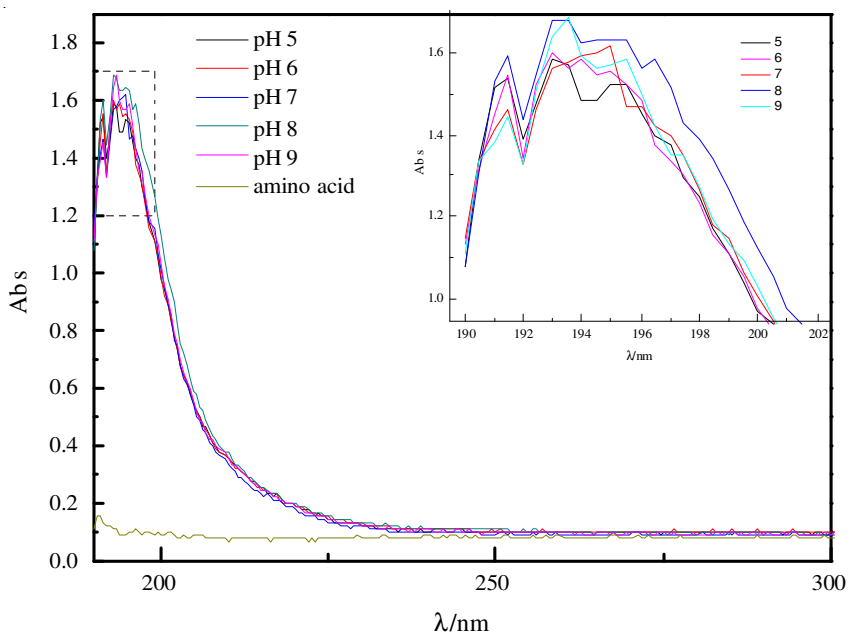

Fig. 7. UV spectra of amino acid adsorbed by hydroxyapatite in different $\mathrm{pH}$

TABLE-1

pH VALUES OF VARIOUS PARTS OF HUMAN BODY FLUID

\begin{tabular}{cccc} 
Parts of human body & Blood & Bone & Saliva \\
\hline $\mathrm{pH}$ value & $7.35-7.45$ & $7.30-7.50$ & $6.50-7.50$
\end{tabular}

As shown in Fig. 8, hydroxyapatite powders with different concentration had obviously adsorption ability for amino acid. Among them, the adsorption ability of hydroxyapatite powders with the amount of $400 \mathrm{mg}$ for $100 \mathrm{~mL}$ of amino acid was the strongest. This indicated that the influence of hydroxyapatite concentration on its adsorption for amino acid was complex. Each hydroxyapatite molecular adsorbed a large amount of amino acid in the surfaces with small amount of hydroxyapatite in amino acid solution, which was enough to make it suspend to upper solution and form soluble molecules. While the amount of hydroxyapatite in amino acid solution increases, the amount of amino acid adsorbed in the surfaces of hydroxyapatite molecular reduced and the hydroxyapatite molecular could not suspend to upper solution to form soluble molecules. Eventually the hydroxyapatite molecular sank into the hydroxyapatite powders which did not be adsorbed.

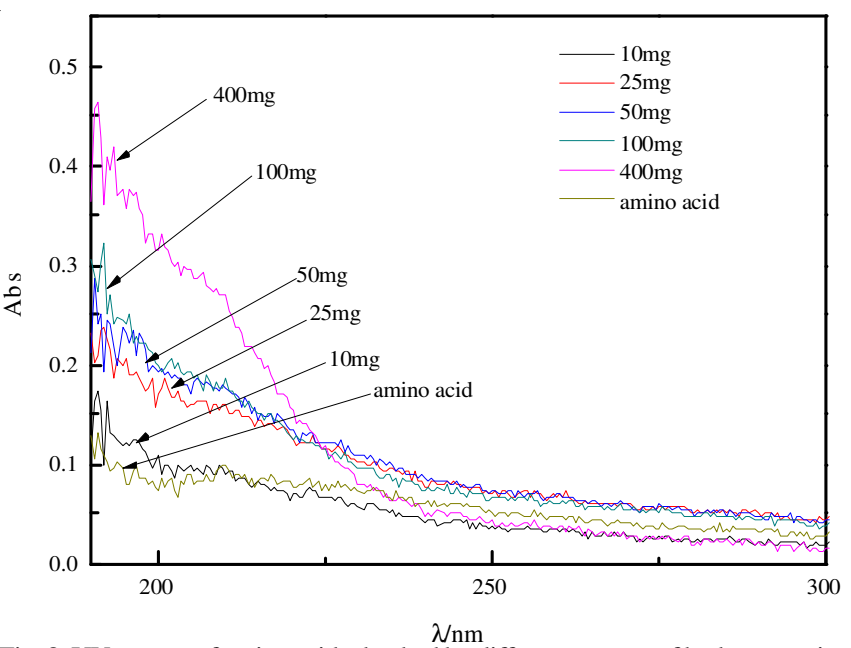

Fig. 8. UV spectra of amino acid adsorbed by different amount of hydroxyapatite

Fig. 9 shows UV spectra of amino acid with different concentration adsorbed by hydroxyapatite powders. The analysis results showed that the adsorption activity of hydroxyapatite powders gradually reduced with the increase of concentration of amino acid solution. When the concentration of the amino acid solution was more than $50 \mathrm{mg} / \mathrm{L}$, the adsorption activity of hydroxyapatite gradually reduced.

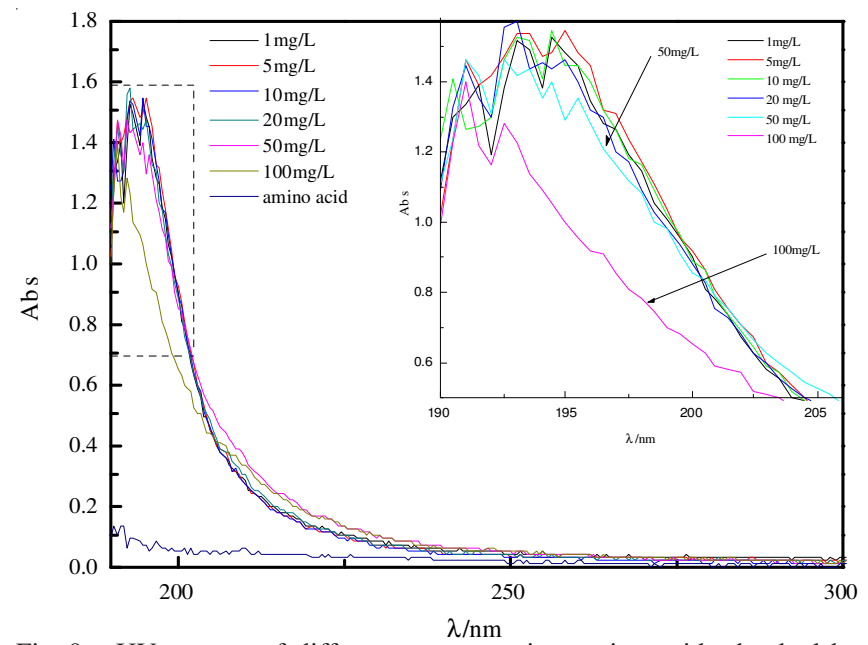

Fig. 9. UV spectra of different concentration amino acid adsorbed by hydroxyapatite powders 
As shown in Fig. 10, the adsorption activities of hydroxyapatite powders obviously increased after substituted by trace elements. And hydroxyapatite powders substituted by different ion had different adsorption ability for amino acid. Among them, adsorption activity of Zn-hydroxyapatite was best, Fehydroxyapatite was the second and Mn-hydroxyapatite was the worst. This revealed that the biocompatibilities of hydroxyapatite powders substituted by trace elements in the human body increased. The structure distortion degree and the crystallization degree of hydroxyapatite substituted by different elements were different, so the adsorption activities and biological activity of hydroxyapatite were different. The crystal structure of hydroxyapatite distorted after substituted by trace elements. It is in good agreement with the results obtained from XRD data.

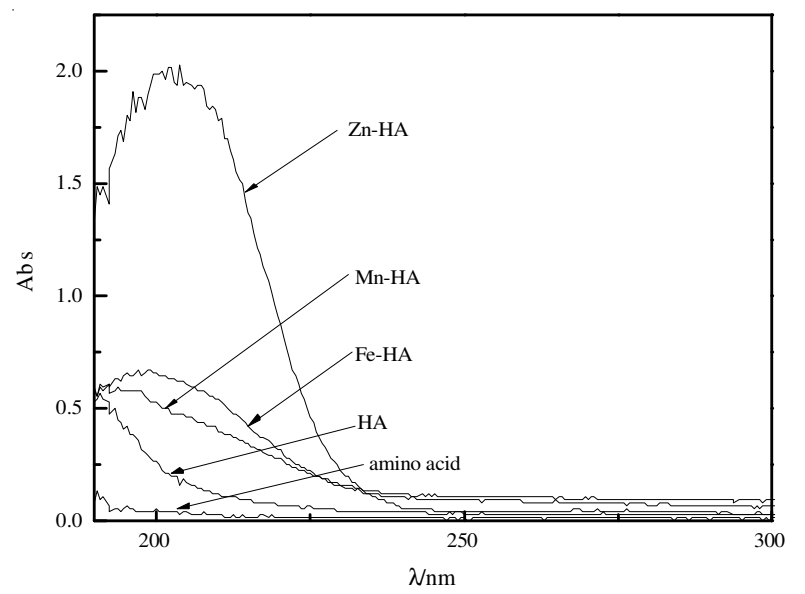

Fig. 10. UV spectra of amino acid adsorbed by substituted hydroxyapatite (HA) powders

The UV spectra of amino acid adsorbed by Zn-hydroxyapatite powders are shown in Fig. 11. It could be seen that the adsorption activities of Zn-hydroxyapatite powders were significantly higher than the hydroxyapatite powders. And with the increase of the amount of zinc, the adsorption activity increased apparently. At the same time, the increased zinc amount caused the maximum absorption wavelength for amino acid red shift. This might be because the substitution $\mathrm{Zn}$ for $\mathrm{Ca}$ reduced the crystallinity of hydroxyapatite and the ultraviolet absorption mechanism changed.

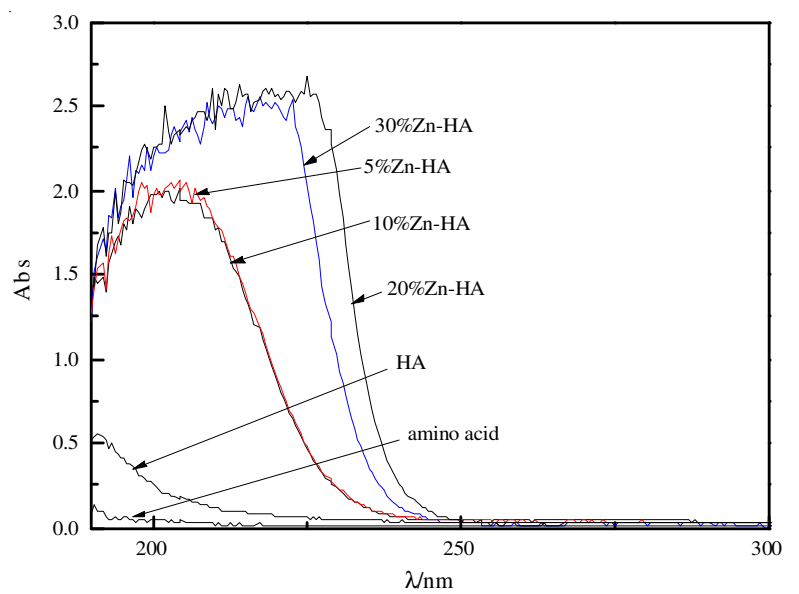

Fig. 11. UV spectra of amino acid adsorbed by Zn-hydroxyapatite (HA) powders

\section{Conclusion}

In this study, zinc, manganese and ferrus substituted hydroxyapatite independently have been prepared by via solgel method and characterized by XRD, SEM and UV for its crystal structure, morphology and biological activity. The XRD analyses revealed that the samples consisted of hydroxyapatite with good crystalline phase. The crystallinity of hydroxyapatite varied with the concentration of $\mathrm{Ca}\left(\mathrm{NO}_{3}\right)_{2}$ for preparation and $0.5 \mathrm{~mol} / \mathrm{L}$ was the best synthetic concentration. Zinc, manganese and ferrus substitution caused lattice disorder in the hydroxyapatite structure and both displayed an inhibiting effect on the crystallization of hydroxyapatite which reduced the crystallite size and crystallinity. SEM results showed zinc, manganese and ferrus substitution in hydroxyapatite reduced the particles size and increase the specific surface area of hydroxyapatite. Biological activity studies evidenced hydroxyapatite had obvious adsorption for amino acid and the presence of zinc, manganese and ferrus in hydroxyapatite improved the biological activity of hydroxyapatite. Moreover, the adsorption time of hydroxyapatite was short and the effect of $\mathrm{pH}$ on the adsorption was not apparent. By adjusting the concentration of substitution elements it may be possible to achieve desired properties for different biomedical applications.

\section{ACKNOWLEDGEMENTS}

The authors gratefully acknowledged the support of Science and Technology Research Key Project for Colleges and Universities in Hebei Province of China (ZD2010218); Doctoral Foundation for Youths of Hebei Normal University of Science \& Technology of China (2009 YB003). The authors also thank Analysis and Test Center of Hebei Normal University of Science \& Technology of China for analyzing samples.

\section{REFERENCES}

1. M. Itokazu, W. Yang, T. Aoki and N. Kato, Biomaterials, 19, 19817 (1998).

2. E. Boanini, M. Gazzano and A. Bigi, Acta Biomater, 6, 1882 (2010).

3. F. Ren, R. Xin, X. Ge and Y. Leng, Acta Biomater., 5, 3141 (2009).

4. N.Y. Mostafa, H.M. Hassan and F.H. Mohamed, J. Alloys Comp., 479, 692 (2009).

5. M. Wakamura, K. Hashimoto and T. Watanabe, Langmuir, 19, 3428 (2003).

6. H.B. Pan, Z.Y. Li, W.M. Lam, J.C. Wong, B.W. Darvell, K.D.K. Luk and W.W. Lu, Acta Biomater, 5, 1678 (2009).

7. F. Balas, J.P. Pariente and M.V. Regi, J. Biomed. Mater. Res., 66A, 364 (2003).

8. A. Bianco, I. Cacciotti, M. Lombardi, L. Montanaro, E. Bemporad and M. Sebastiani, Ceram. Int., 36, 313 (2010).

9. M.H. Fathi and E.M. Zahrani, J. Crystal Growth, 311, 1392 (2009).

10. I. Cacciotti, A. Bianco, M. Lombardi and L. Montanaro, J. Eur. Ceram. Soc., 29, 2969 (2009).

11. A. Ito, M. Otsuka, H. Kawamura, M. Ikeuchi, H. Ohgushi, Y. Sogo and N. Ichinose, Curr. Appl. Phys., 5, 402 (2005).

12. Y. Sogo, T. Sakurai, K. Onuma and A. Ito, J. Biomed. Mater. Res., 62 , 457 (2002)

13. B.S. Moonga and D.W. Dempsteri, J. Bone Miner. Res., 10, 453 (1995).

14. R. Chung, M. Hsieh, K. Huang, L. Perang, F. Chou and T. Chin, J. Sol-Gel. Sci. Technol., 33, 229 (2005).

15. S. Dasgupta, S.S. Banerjee, A. Bandyopadhyay and S. Bose, Langmuir, 26, 4958 (2010).

16. Y. Doi, T. Shibutani, Y. Moriwaki, T. Kajimoto and Y. Iwayama, J. Biomed. Mater. Res., 39, 603 (1998).

17. J. Barralet, S. Best and W. Bonfield, J. Biomed. Mater. Res., 41, 79 (1998). 